\title{
Effectiveness of implementing evidence based practices guidelines regarding blood transfusion on quality of nursing care and patients' safety in Pediatric Units
}

\author{
Orban Ragab Bayoumi, Nahed Saied Mohamed El-Nagger* \\ Department of Pediatric Nursing, Faculty of Nursing, Ain Shams University, Egypt
}

Received: April 25, 2020

DOI: $10.5430 /$ jnep.v10n10p33
Accepted: June 21, 2020

Online Published: June 27, 2020

URL: https://doi.org/10.5430/jnep.v10n10p33

\begin{abstract}
Background and objective: The new trend that widely accepted in health care institutions is to implement an evidence-based practice. Health facilities frequently integrate standards of practice that reveal current best evidence to increase patients' outcomes and consequently decrease hospital cost. Transfusion of blood is a cornerstone in managing many critically ill children. However, nurses have a chief role in transfusing blood and their knowledge and performance are important for them to transfuse blood safely and efficiently. Aim: Evaluate the effectiveness of implementing evidence based nursing practices guidelines on quality of nursing care and patients' safety as regards blood transfusion to improve transfusion practices and ensure safety.

Methods: A quasi-experimental design. Settings: This study was conducted at Pediatric Intensive Care Unit, Neonatal Intensive Care Unit, Emergency Room, Medical and Surgical Wards, Hematology/Oncology Units in Children Hospital affiliated to Ain Shams University Hospitals. Sample: A convenience sample composed of 95 pediatric nurses, whom were willingness to participate in the study and 78 children whom were receiving blood transfusion. Tools: I. A Self-Administered Questionnaire Sheet to assess nurses' knowledge regarding blood transfusion; II. Child's Medical Record to collect data about child's health status; III. An Observational Competence Checklist to assess the quality of actual nurses' practices about Blood Transfusion; and IV. Evidence Based Nursing Practices Guidelines of Blood Transfusion that was described the EBNP guidelines that provide a standardized approach for transfusion (before and after).

Results: The studied nurses' knowledge and practices regarding to blood transfusion were improved and reflected a highly significant differences before and after guidelines implementation.

Conclusions: The present study concluded that studied nurses showed an improvement in their knowledge and practices regarding blood transfusion after implementation of evidence based nursing practices guidelines. Recommendation: It is essential that all nurses who administer blood transfusion for children should complete periodic in-services training programs to keep them up to date regarding to safe and efficient administration of blood transfusion.
\end{abstract}

Key Words: Blood transfusion, Evidence based nursing practices guidelines, Quality of nursing care, Patients'safety, Pediatric units

\section{INTRODUCTION}

Evidence Based Nursing (EBN) is a key element of quality improvement in nursing practices and the gold standard of professional nursing care. EBN is the integration of best research evidence into practice with clinical expertise and patient's values to facilitate clinical decision-making. ${ }^{[1,2]}$ The

\footnotetext{
*Correspondence: Nahed Saied Mohamed El-Nagger; Email: nahidalngar@yahoo.com; Address: Department of Pediatric Nursing, Faculty of Nursing, Ain Shams University, Egypt.
} 
new trend that widely accepted in health care settings is to implement Evidence Based Practice (EBP). Health facilities frequently integrates standards of practices that reveal current best evidence to improve patients' outcomes and consequently decrease hospital cost. So, many organizations seek nurses to implement EBN in their practice for improving patient outcomes. ${ }^{[3-5]}$

Blood transfusion (BT) is a highly effective and an important aspect of daily nurses' clinical practices. Blood and blood products provide unique therapeutic benefits to pediatric patients. Whereas, more than 2,700 pediatric patients receive blood transfusions yearly, including nearly 7,500 red blood cell, 3,000 platelets, 2,000 plasma, and 900 cryoprecipitate units. ${ }^{[2,6]}$

Blood transfusion can be lifesaving treatment for children in hospitals, but its use is associated with a number of risks such as; blood reactions, transmission of infectious agents and cardiac failure. ${ }^{[4]}$ BT is usually accompanies with stress, because many hospitals do not have clear guidelines regarding administration of blood products or monitoring of children receiving blood. In addition to lack of knowledge of various aspects of blood transfusion by clinical staff, including nurses continues to be a real threat to patient safety. ${ }^{[8,9]}$

Critically ill children in the Pediatric Intensive Care Unit (PICU) may be commonly indicated for blood product transfusion for maintenance of the Hemoglobin $(\mathrm{Hb})$ level and oxygen-carrying capacity; restoration of blood volume and cardiovascular function; and for normal hemostatic function. ${ }^{[3,10,11]}$ Serious complications resulting from transfusion may encountered and the safety of blood products has become a very important issue, especially in the neonatal field. ${ }^{[7,12]}$ Blood transfusion is safe when it is donated by a carefully selected, healthy donor; free from infections that could be harmful to the recipient; processed by reliable methods of testing, component production, storage and transportation; transfused only upon need and for the patient's health and wellbeing. ${ }^{[13,14]}$

Despite evidence based supporting a restrictive transfusion threshold and associated clinical practice guidelines. Multiple factors may influence adherence to EBNP, including patient characteristics, nurses' knowledge and experience, unit organization and team communication. Therefore, a clear understanding of such factors is critical for improving adherence to best transfusions practices. ${ }^{[8,15]}$

The safe supply of blood and blood products is vital to Egypt's health system as it is used in the management of different diseases. ${ }^{[16]}$ The mortality and morbidity, in addition to the cost associated with administering BT practices requires that pediatric nurses needs to be up to date their knowledge and practices through implementing EBP to provide care in a cost effective manner to improve the health outcomes and patient's safety. ${ }^{[17,18]}$

Pre transfusion, clinical assessment and all verifying information matches exactly are required, record for type and volume of blood products transfused and donation numbers of products transfused. Monitoring the child before starting the transfusion 15 minutes after starting transfusion carefully to detect early any transfusion reactions., during transfusion at least every hour, in addition to 4-6 hours after completing the transfusion the child must assess to ensure that the results of the transfusion are appropriate. ${ }^{[19,20]}$ At each of these stages, document the following data in the child's record; child's general appearance, vital signs, fluids balance for intake and output. ${ }^{[15,16]}$ As well as, the infusion should start slowly at a rate less than or equal to $5 \mathrm{ml} / \mathrm{min}$ for the first 15 minutes and the child should observed closely throughout the transfusion. ${ }^{[17,21]}$

Nurses have a vital role in administering BT, their performance and knowledge are crucial to transfuse blood safely and efficiently. ${ }^{[3,5,22]}$ Professional nurses plays a primary role in safety and effective blood administration, as well as protecting the children from the potential complications, moreover they are responsible for initiating, maintaining, monitoring and discontinuing the BT. ${ }^{[10,11]}$ Therefore, there is a need for educational programs that educate the nurses on BT updating safety guidelines and errors' reduction, also it is important that their knowledge and performance regularly evaluated. ${ }^{[5,23]}$

Consequently, pediatric nurses must be empowered with the current best evidence for BT practice in the pediatric critical care units. Empowering nurses with updating knowledge as regards BT risks and triggers may lead to early diagnosis, rapid intervention when adverse events occur, and integration of literature that supported care delivery. ${ }^{[24,25]}$

Nurses play a crucial role both directly related to the transfusion and identification for the complications of transfusion. ${ }^{[22,26]}$ So, a coordinated team effort by practitioner nurses, BT experts, other laboratory personnel and health care providers involved in the transfusion is needed in order to implement guidelines for standard BT practices. ${ }^{[24,27]}$ Because many nurses have not readily incorporated these recommendations into their practices. It is important to the professions of nursing to evaluate nurses' knowledge on current blood transfusion recommendations and adverse events. ${ }^{[5,28]}$ Moreover, education of a standard practices guidelines is vital to improve the quality of nursing care and ensure patient's safety during BT. ${ }^{[3,5]}$ 


\subsection{Significance of the study}

Blood transfusion is an essential but is a serious procedure in management used to treat various health problems of children. Countless efforts are carry out to pledge the quality of the transfusion process and patient's safety. Transfusion of blood products is a cornerstone in managing up to $45 \%$ of critically ill children in Hematology \& Oncology Units and PICUs, $35 \%$ in NICUs and $12 \%$ in Emergency Rooms (ER). ${ }^{[29,30]}$

Pediatric patient safety is a vital part in health care delivery. So, the use of EBP transfusion guidelines has advocated as a way to improve transfusion practices. Whereas, evidence suggests that human error remains the major cause of morbidity and mortality associated with transfusion of blood products practices that can leads to serious consequences for sick children. The risk of wrong transfusion in many times greater than the risk of Human Immune Virus (HIV) transmission by blood. ${ }^{[31]}$ Hence, both administrative and clinical errors can be reduced by adhering to transfusion guidelines. $^{[3,32]}$ Consequently, educating and training of the pediatric nursing staff providing BT represent a core issue in establishing an efficient and safe transfusion administration. Also, the use of EBP transfusion guidelines should give the staff theoretical basis and technical skills to ensure safe and efficient transfusion practices. ${ }^{[33,34]}$

\subsection{Aim of the study}

The aim of this study was to evaluate the effectiveness of implementing evidence based nursing practices guidelines on quality of nursing care and patients' safety as regards blood transfusion to improve transfusion practices and ensure safety through:

1) Assessing the pediatric nurses' knowledge and practices as regards administration of blood transfusion.

2) Identifying the common pediatric nurses' practical errors related to blood transfusion administration to maintain pediatric patients' safety.

3) Implementing blood transfusion evidence based nursing practices guidelines for nurses working in pediatric units to ensure safe practices for the administration of blood transfusion.

\subsection{Research hypothesis}

This study hypothesized that implementation of evidence based nursing practices guidelines regarding blood transfusion will be associated with positive effect on improving nurses' knowledge and practices at different pediatric care settings that reflects on quality of nursing care and pediatric patients' safety.

Published by Sciedu Press

\section{SUBJECTS AND METHODS}

\subsection{Research design}

A quasi-experimental study, before and after implementation was conducted.

\subsection{Research settings}

This study was conducted at Pediatric Intensive Care Unit (PICU), Neonatal Intensive Care Unit (NICU), Emergency Room (ER), Medical and Surgical Wards, and Hematology /Oncology Units in Children's Hospital affiliated to Ain Shams University Hospitals.

\subsection{Research subjects}

A convenience sample of 95 pediatric nurses from previously mentioned settings who willingness to participate in the study and 78 neonates and children receiving blood transfusion. The nurses were representative from different pediatric care settings as follows: 20 nurses were working in Hematology/ Oncology Units, 20 nurses were working in Emergency Room, 35 nurses were working in PICU/ NICU and 20 nurses were working in Pediatric Medical \& Surgical Wards.

\subsection{Research tools}

Tool I: A Self-Administered Questionnaire Sheet (before and after guidelines implementation): The researchers were designed it in an Arabic language based on updated literatures to assess nurses' knowledge regarding blood transfusion. It comprised two parts:

Part A: Demographic characteristics of nurses such as their age, qualification, experience, and previous receiving for training programs about BT.

Part B: Nurses' knowledge regarding blood transfusion including components of blood, functions of blood elements, indications of different components, blood storage, donation, requirements and precautions for transfusion, complications associated with transfusion, as well as the nurses' role before, during and after BT.

The nurses interviewed individually or in groups that entail 2-3 nurses according to their availability and readiness. Questionnaire was administering before implementation of BT evidence based nursing practices guidelines (EBNP) to obtain a base line assessment data for nurses' level of knowledge and within 2 weeks after implementation of the EBNP. The nurse filled in the questionnaire and it took 15-20 minutes.

The self-administered questionnaire sheet includes 50 questions. The total score of all questions was 50 grades (equal $100 \%$ ). The nurses' answers then checked using a model key answer, each correct answer scored "one" and wrong answer scored "zero". Accordingly, their total knowledge 
were categorized into satisfactory knowledge scored $\geq 80 \%$ and unsatisfactory knowledge scored $<80 \%$.

Tool II: Child's Medical Record: It was used to collect data about child's health status as regards child's age, gender, diagnosis, etc.

Tool III: An Observational Competence Checklist of Blood Transfusion (before and after EBNP implementation): It was adopted from Huband et al. (2018) ${ }^{[27]}$ and Bowden and Greenberg (2017). ${ }^{[29]}$ It was used to assess the quality of actual nurses' practices before, during and after BT; also their practices if there was any blood transfusion reactions, and to identify the common nurses' practical errors related to BT. Time consumed for assessing each procedure was 5-15 minutes.

The total score of observation checklists was 40 grades (equal $100 \%$ ). Score "one" given for each correct step and "zero" if nurses practices incorrectly done or not done. Accordingly, the total score of nurses' practices was converted into percentage and categorized into $\geq 85 \%$ considered competent, and $<85 \%$ considered incompetent, that reflected the quality of nursing care.

Tool IV: Evidence Based Nursing Practices Guidelines of Blood Transfusion: It was a adopted from Simancas-Racines et al. (2018) ${ }^{[15]}$ and British Committee for Standards in Hematology (BSCH) (2015). ${ }^{[16]}$ It was described the EBNP guidelines that provide a standardized approach for transfusion. They also contain protocols for the investigation and treatment of adverse blood transfusion reactions.

\subsection{Operational phase}

An approval was obtained from the hospital manager and head of nursing departments in the previously mentioned study settings. Also, voluntary acceptance of the nurses was a pre-requisite to participate in the study and an oral consent from the parents of children.

\subsection{Pilot study}

A pilot study was carried out on $10 \%$ of the study subjects involved 10 nurses and 8 children for testing the study tools for its clarity, objectivity, required time, and applicability The necessary modifications were done according to the pilot study results and the subjects included in the pilot study were excluded later from the study sample.

\subsection{Procedures of the study}

The study procedure was carried out as the following:

I. Pre intervention phase of EBNP:

-The researchers were using Stetler model for raising nurses' awareness about the importance of utilizing research findings into nursing practices. The researchers were searching for relevant research-based evidence nursing and medical databases including the Cochrane Library, CINAHL, and MEDLINE. (Singapore Ministry of Health, 2019). ${ }^{[2]}$ Available from: https://www.guidelinecentral.com/sum maries/clinical-blood-transfusion/\#section-4 42.MOH_Inf@MOH.gov.sg. Whereas, the Stetler Model focuses on the use of EB and critical thinking to provide care and change practice in addition to improve patient's safety outcomes. This model was applied in both educational and clinical forms of practice and follows a five phases to promote evidence-based practices: (1) preparation, (2) validation, (3) decision-making, (4) application, and (5) evaluation. Which described as the following:

1) Preparation:

-The researchers were preparing the study tools in the form of a self- administered questionnaire, observational competence checklists regarding BT and Power Point presentation regarding blood transfusion guidelines.

-The researchers were using the PICO format to generate a comprehensive a answerable clinical question that includes: (a) patient population, (b) intervention of interest, (c) comparison intervention, and (d) outcomes.

-Population $(\mathrm{P})$ : The target population is a convenience sample of nurses who administer blood transfusion for children in different pediatric care settings.

-Intervention (I): Applying of EBNP guidelines. A Power Point presentation was using during the sessions.

-Comparison (C): Comparing between nurses' practices in different pediatric care settings before and after implementation of EBNP guidelines regarding blood transfusion.

-Outcomes (O): Assessing the level of nurses' knowledge and practices that reflects as a measurement indicator on their quality of nursing care and patient's safety.

2) Validation:

Content validity was established from five academic staff members and professional nurses for their opinions regarding the research tools. Their comments leads to modifications of some items. Assessing the reliability of the tools by calculating the Cronbach's Alpha, which is 0.945 for the questionnaire and 0.90 for competence checklists.

3) Decision-Making:

The researchers made the required changes in response to expert's opinions, then they deciding to use the study tools for assessing the nurses' knowledge and practices regarding administration of BT.

II. Intervention phase for EBNP Guidelines:

4) Application: 
-After the official approval was obtained, the nature and purpose of the study were explained for the studied nurses. The researchers assessed the nurses' knowledge and practices regarding blood transfusion by using the study tools (before). The questionnaire sheet was filled in the clinical area by the studied nurses in the presence of the researchers. The observation checklist was filled out by the researchers who were available 2 days per week alternatively in different study settings to assess the actual nurses' practices on children for identifying the common pediatric nurses' practical errors related to BT administration.

-Data collection done before and after EB clinical practices guidelines implementation from September 2018 to February 2019.

-The assessment was done over a 2 weeks period. The total numbers of nurses were 95, divided into ten groups (each group involved 9-10 nurses) according to the study settings. Each group took an overview about an EBN approach in relation to blood transfusion, through the next one session. The session started according to nurses' physical and mental readiness taking into consideration the mitigating circumstances of their work at the study settings.

-The application of EBNP guidelines was carried out for each group separately through four successive sessions. The duration of each session took approximately one hour, the researchers illustrated the theoretical part related to blood and blood products, blood functions, indications and contraindications of BT, complications of BT, manifestation of BT reactions, nurses' role and child's safety measures during BT. Also precautions before, during and after transfusion, general guidelines in management of adverse effects of blood transfusion reactions in two sessions through using different teaching strategies and media (Modified Lecture, group discussion, handout, Video film, PowerPoint presentation, Figures, Brain storming and Critical thinking).

-These sessions followed by six practical demonstration and re- demonstrated sessions related to blood transfusion nursing practices guidelines (before, during and after blood transfusion) by the researchers at the clinical settings. At the end of these sessions, all participant nurses provided with a CD containing the power point presentation of clinical practices guidelines regarding BT.

III. Post intervention phase of EBNP:

5) Evaluation:

The researchers evaluated the quality of nursing care and child's safety outcomes after application of EBNP guidelines through assessing the nurses' knowledge and practices by using the same study tools through two weeks (after).

Published by Sciedu Press

\subsection{Ethical considerations and human rights}

Obtaining the required permission for carrying out the study from the study settings, whereas the researchers clarified the aim, objectives and expected outcomes for nursing administrators for their cooperation. A clear and simple clarification provided to each participant nurse. The researchers confirmed the confidentiality of all information and used for research purpose only, and nurses had the right to withdraw from the study at any phase and an informed oral consent obtained prior to their inclusion in the study.

\subsection{Limitation of the study}

The study should be replicated on large sample and different hospitals settings in order to generalize the results.

\subsection{Statistical analysis}

Data were organized, tabulated, coded and analyzed by using SPSS version 21. Descriptive statistics (frequency numbers and percentages) identified demographic characteristics and nurses' responses to the questionnaire. The mean, standard deviation, Chi square $\left(\chi^{2}\right)$ and Paired $t$-tests used and statistical significant was set at $p$-value $<.05$.

\section{RESULTS}

Table 1 clarified that the mean nurses' age was $30.99 \pm 6.12$, and most of them their years of experience ranges between one year and less than 20 years with mean $9.28 \pm 5.31$ years. Concerning nurses' qualifications, this table also showed that more than half $(57.89 \%)$ of them had nursing school diploma, also the minority $(17.4 \%)$ of them receiving previous training programs related to blood transfusion.

Table 2 illustrated that approximately less than three fourths $(71.8 \%)$ of children age was less than six years and more than half $(58.97 \%)$ of them were boys, also slightly more than half $(51.28 \%)$ of children were diagnosed as an anemic children and very few $(2.56 \%)$ of them had trauma.

Figure 1 showed that the total nurses' knowledge as regards blood transfusion before the guidelines implementation was $71.57 \%$ compared to $93.68 \%$ that reflected significant improvement in all items of the nurses' knowledge after the guidelines implementation at $p<.001$.

Table 3 displayed that the mean score of satisfactory nurses' knowledge regarding to hazards of transfusion, there was a highly significant difference in nurses' knowledge before and after guidelines implementation at $p<.001$.

As noticed in Table 4, there was significant improvement in the mean score of satisfactory nurses' knowledge regarding strategy for blood transfusion safety before and after guidelines implementation that indicated a highly statisti- 
cally significant difference at $p<.00$.

Table 1. Characteristics of the studied nurses

\begin{tabular}{lll}
\hline \multirow{2}{*}{ Nurses' Characteristics } & \multicolumn{2}{l}{ Total number of nurses 95 (100\%) } \\
\cline { 2 - 3 } Age (years): & No. \\
$20-<25$ & 10 & 10.52 \\
$25-<30$ & 38 & 40 \\
$30-<35$ & 29 & 30.54 \\
35 and more & 18 & 18.94 \\
Mean \pm SD 30.99 \pm 6.12 & & \\
Experience (Years): & & \\
1 - <5 & 18 & 18.94 \\
$5-<10$ & 40 & 42.12 \\
$10-<15$ & 20 & 21.05 \\
$15-<20$ & 9 & 9.47 \\
20 and more & 8 & 8.42 \\
Mean \pm SD 9.28 \pm 5.31 & & \\
Nurses' Qualifications: & & \\
Nursing School Diploma & 55 & 57.89 \\
Bachelor of Nursing & 40 & 42.11 \\
Nurses’ place of work: & & \\
Hematology/Oncology & 20 & 21.05 \\
Units. & 20 & 21.05 \\
ER. & 35 & 36.84 \\
NICU/PICU. & 20 & 21.05 \\
Medical/Surgical wards. & & \\
Attended training courses & 14 & \\
\hline
\end{tabular}

Table 5 demonstrated that there was statistical significant difference before and after guidelines implementation at $p$ $<.001$, as regards the total mean score of competent nurses' practices related to blood transfusion.

As regards errors in nurses' practices before, during and after blood transfusion, Table 6 revealed that significant improvement observed among the studied nurses after guidelines implementation at $p<.001$.

Table 7 showed that there was a highly statistical significant difference before and after guidelines implementation regarding to mean score of competent nurses' practices if detecting any signs or symptoms of blood transfusion reaction at $p<$ .001 .

Table 2. Characteristics of the studied children

\begin{tabular}{lll}
\hline \multirow{2}{*}{ Child's Characteristics } & \multicolumn{2}{l}{ Total number of children $\mathbf{7 8} \mathbf{( 1 0 0 \% )}$} \\
\cline { 2 - 3 } & No. & \\
\hline Child's age in years: & & 37.2 \\
$<1$. & 29 & 34.6 \\
1: $<6$. & 27 & 20.5 \\
6: $<12$. & 16 & 7.7 \\
12 and more & 6 & \\
Mean \pm SD 26.4 \pm 8.0 & & 58.97 \\
Gender: & & 41.03 \\
Boys & 46 & \\
Girls & 32 & 64.10 \\
Educational level: & & 25.64 \\
No & 50 & 10.26 \\
Preparatory & 20 & \\
Secondary & 8 & 51.28 \\
Diagnosis: & $* *$ & 2.56 \\
Anemia & 40 & 28.20 \\
Trauma & 2 & 15.38 \\
Leukemia & 22 & 23.07 \\
Thalassemia & 12 & 14.10 \\
Intestinal Obstruction & 18 & 8.97 \\
Renal disorders & 11 & \\
Septicemia & 7 & \\
\hline
\end{tabular}

**Number were mutually exclusive

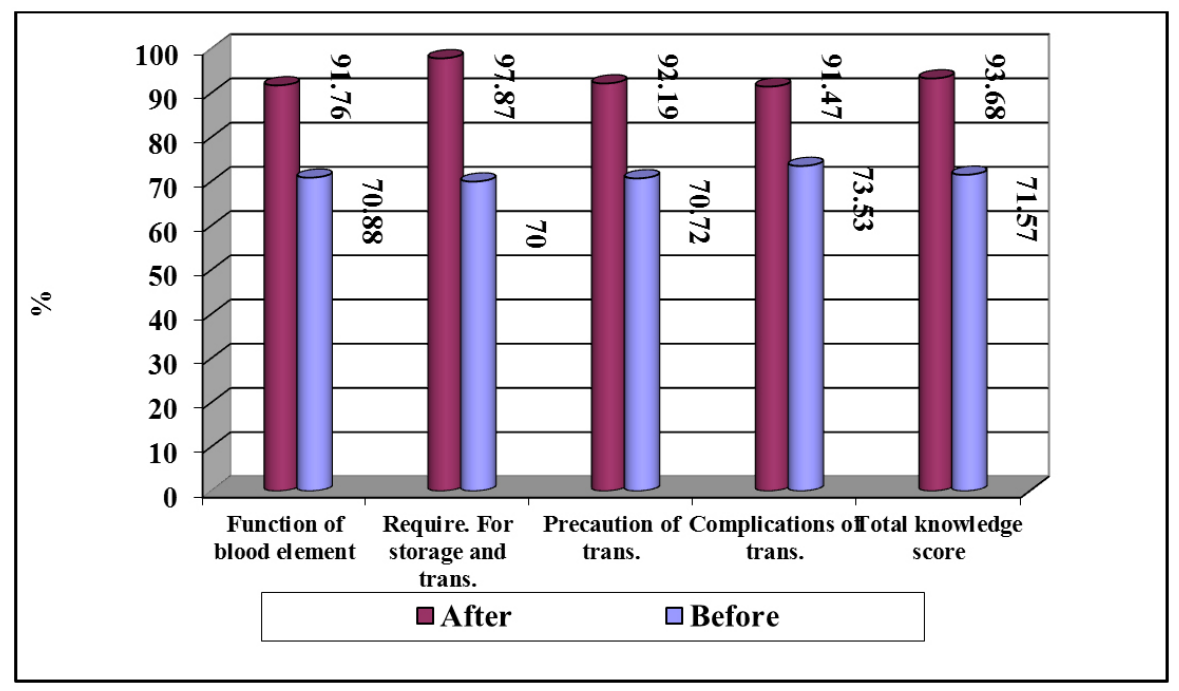

Figure 1. Total nurses' knowledge and sub items knowledge as regards blood transfusion before and after guidelines implementation 
Table 3. Mean score of satisfactory nurses' knowledge as regards hazards of transfusion before and after guidelines implementation

\begin{tabular}{llll}
\hline \multirow{2}{*}{ Nurses' knowledge as Regards Hazards of Transfusion } & \multicolumn{3}{l}{ Satisfactory knowledge $\geq \mathbf{8 0} \%$} \\
\cline { 2 - 3 } & \multicolumn{1}{l}{ Before } & \multicolumn{1}{c}{ After } \\
\cline { 2 - 3 } & Mean \pm -test & Mean \pm SD \\
\hline Immediate hemolytic transfusion reaction. & $53.5 \pm 15.1$ & $88.9 \pm 7.2$ & $18.6^{*}$ \\
Delayed hemolytic transfusion reaction. & $52.2 \pm 14.2$ & $87.7 \pm 10.1$ & $18.02^{*}$ \\
Febrile and allergic reactions. & $52.6 \pm 14.5$ & $87.1 \pm 11.1$ & $17.6^{*}$ \\
Blood borne infections & $53.5 \pm 15.1$ & $85.4 \pm 13.7$ & $15.7^{*}$ \\
Hypotensive and anaphylactic reaction: & $51.3 \pm 13.5$ & $87.7 \pm 10.1$ & $15.5^{*}$ \\
Post-transfusion purpura. & $52.2 \pm 14.2$ & $87.1 \pm 11.1$ & $17.8^{*}$ \\
Transfusion-associated graft vs. host disease. & $53.5 \pm 15.1$ & $87.7 \pm 10.1$ & $15.7^{*}$ \\
Transfusion-related iron overload. & $52.2 \pm 14.2$ & $87.5 \pm 10.0$ & $18.02^{*}$ \\
Transfusion-related acute lung injury. & $56.7 \pm 16.4$ & & $14.5^{*}$ \\
\hline
\end{tabular}

${ }^{*} p<.001$ = highly statistically significant difference.

Table 4. Mean score of satisfactory nurses' knowledge regarding strategy for blood transfusion safety before and after guidelines implementation

\begin{tabular}{|c|c|c|c|c|}
\hline \multirow{3}{*}{ Items of knowledge } & \multicolumn{2}{|c|}{ Satisfactory Knowledge $\geq 80 \%$} & \multirow{3}{*}{$t$-test } & \multirow{3}{*}{$p$} \\
\hline & \multirow{2}{*}{$\begin{array}{l}\text { Before } \\
\text { Mean } \pm \text { SD }\end{array}$} & \multirow{2}{*}{$\begin{array}{l}\text { After } \\
\text { Mean } \pm \text { SD }\end{array}$} & & \\
\hline & & & & \\
\hline $\begin{array}{l}\text { Check all aspects of blood grouping and cross matching testing, } \\
\text { component preparation and transportation and storage of blood. }\end{array}$ & $52.6 \pm 14.5$ & $79.04 \pm 19.4$ & 9.8 & $.001 *$ \\
\hline The retention and recruitment of blood donors. & $53.5 \pm 15.1$ & $84.8 \pm 14.5$ & 13.04 & $.001 *$ \\
\hline Blood request form completed accurately and legibly. & $56.7 \pm 16.6$ & $87.7 \pm 10.0$ & 14.1 & $.001^{*}$ \\
\hline Do not immerse the blood in warm water. & $57.4 \pm 16.5$ & $89.5 \pm 10.0$ & 14.1 & $.001 *$ \\
\hline Assess the child pre-transfusion for evidence of cardiac failure carefully. & $55.8 \pm 16.3$ & $87.7 \pm 10.0$ & 14.5 & $.001^{*}$ \\
\hline Calculate for the appropriate amount. & $52.2 \pm 14.2$ & $84.2 \pm 15.1$ & 13.3 & $.001 *$ \\
\hline $\begin{array}{l}\text { Monitor child's respiratory rate, heart rate and Pao2 saturation pre, } \\
\text { during and post transfusion. }\end{array}$ & $53.5 \pm 15.1$ & $82.5 \pm 16.9$ & 11.2 & $.001 *$ \\
\hline The appropriate use and safe administration of blood. & $53.5 \pm 15.1$ & $87.1 \pm 11.1$ & 15.7 & $.001 *$ \\
\hline
\end{tabular}

${ }^{*} p<.001=$ highly statistically significant difference

Table 5. Total mean score of nurses' competency level as regards blood transfusion before and after guidelines implementation

\begin{tabular}{|c|c|c|c|c|c|c|}
\hline \multirow{3}{*}{ Items of practices } & \multicolumn{4}{|c|}{ Nurses' Competency level $\geq 85 \%$} & \multirow{3}{*}{ t-test } & \multirow{3}{*}{$p$} \\
\hline & \multicolumn{2}{|c|}{ Before } & \multicolumn{2}{|c|}{ After } & & \\
\hline & Mean & SD & Mean & SD & & \\
\hline -Verify child's identification. & 68.82 & 21.35 & 91.76 & 6.32 & 3.687 & $.001^{*}$ \\
\hline -Check the child's blood pressure, pulse and temperature. & 70.78 & 15.15 & 91.87 & 3.67 & 5.223 & $.001^{*}$ \\
\hline $\begin{array}{l}\text {-Inspect the blood product for any, clotting, gas bubbles or } \\
\text { any abnormal color before administering. }\end{array}$ & 67.25 & 15.24 & 98.00 & 3.50 & 6.017 & $.001^{*}$ \\
\hline -Warm blood unit to $37^{\circ} \mathrm{C}$ before transfusion. & 68.82 & 21.35 & 91.76 & 6.32 & 3.687 & $.001^{*}$ \\
\hline -Begin transfusion slowly $(1-2 \mathrm{~mL} / \mathrm{min})$ & 70.78 & 15.15 & 91.87 & 3.67 & 5.223 & $.001^{*}$ \\
\hline -Check the child' vital signs. & 70.78 & 15.15 & 91.87 & 3.67 & 5.223 & $.001^{*}$ \\
\hline -Observe the child during the first 15 minutes closely. & 73.53 & 11.84 & 91.18 & 7.47 & 7.606 & $.001 *$ \\
\hline -Transfuse blood within 4 hours. & 67.25 & 15.24 & 98.00 & 3.50 & 6.017 & $.001^{*}$ \\
\hline Total Mean Score of Nurses' Competency Level & 70.28 & 14.49 & 93.20 & 4.29 & 6.267 & $.001^{*}$ \\
\hline
\end{tabular}

${ }^{*} p<.001=$ highly statistically significant difference. 
Table 6. Errors in nurses' practices before, during and after blood transfusion as observed among nurses before and after guidelines implementation

\begin{tabular}{llll}
\hline \multirow{2}{*}{ Nurses' Practices Errors } & Before & After & \multirow{2}{*}{$\boldsymbol{\chi}^{\mathbf{2}}$} \\
\cline { 2 - 3 } & $\mathbf{\%}$ & $\mathbf{\%}$ & \\
\hline Before Blood Transfusion & 75.6 & 2.6 & 85.7 \\
Does not verify patient identification. & 87.2 & 14.1 & $p<.001$ \\
Does not warm blood bag before transfusion. & 71.8 & 0 & \\
Does not label blood bag. & & & \\
During Blood Transfusion & 76.9 & 2.6 & \\
Does not follow aseptic technique. & 69.2 & 2.6 & 82.4 \\
Does not deliver the blood in time of transfusion. & 78.2 & 5.1 & $p<.001$ \\
Does not check and monitor vital signs. & 75.6 & 5.1 & \\
Does not check the intravenous access site continuously. & 87.2 & 11.5 & \\
Does not regulate blood infusion at ordered rate. & 84.6 & 10.3 & \\
Does not closely observe the child for transfusion reactions. & & & \\
After Blood Transfusion & 78.2 & 0 & 62.4 \\
Does not reassess the child for signs and symptoms of transfusion reaction. & 71.8 & 5.1 & $p<.001$ \\
Does not check and monitor vital signs. & 78.2 & 33.3 & \\
Does not observe and obtain the child's vital signs in the first five minutes. & & & \\
\hline
\end{tabular}

Table 7. Mean score of nurses' competency level regarding signs and symptoms of blood transfusion reactions before and after guidelines implementation

\begin{tabular}{|c|c|c|c|}
\hline \multirow{3}{*}{ Items of Practices } & \multicolumn{2}{|c|}{ Nurses' Competency level $\geq 85 \%$} & \multirow{3}{*}{ t-test } \\
\hline & Before & After & \\
\hline & Mean \pm SD & Mean \pm SD & \\
\hline Stop the transfusion immediately, and notify the physician. & $54.7 \pm 16.3$ & $86.9 \pm 10.0$ & $\begin{array}{l}14.5 \\
p<.001\end{array}$ \\
\hline Check and monitor vital signs. & $57.4 \pm 16.5$ & $89.5 \pm 10.0$ & $\begin{array}{l}14.1 \\
p<.001\end{array}$ \\
\hline $\begin{array}{l}\text { Disconnect the transfusion set-but keep the IV line open with new infusion } \\
\text { of normal saline solution, using new tubing. }\end{array}$ & $53.5 \pm 15.1$ & $86.8 \pm 14.5$ & $\begin{array}{l}13.04 \\
p<.001\end{array}$ \\
\hline $\begin{array}{l}\text { Send the blood bag and tubing to the blood bank for repeat typing and } \\
\text { culture. }\end{array}$ & $54.4 \pm 15$ & $87.6 \pm 10.0$ & $\begin{array}{l}15.9 \\
p<.001\end{array}$ \\
\hline Draw another blood sample for plasma hemoglobin, culture, and retyping. & $52.6 \pm 14.5$ & $79.04 \pm 19.4$ & $\begin{array}{l}9.8 \\
p<.001\end{array}$ \\
\hline Continues to monitor vital signs frequently. & $54.4 \pm 15.6$ & $87.7 \pm 10.0$ & $\begin{array}{l}15.9 \\
p<.001\end{array}$ \\
\hline Administers medications as prescribed & $56.7 \pm 16.4$ & $87.5 \pm 10.0$ & $\begin{array}{l}14.5 \\
p<.001\end{array}$ \\
\hline
\end{tabular}

Table 8 revealed there was an improvement in nurses' practices concerning the mean score of nurses' competency level regarding implementation of evidence-based guidelines for standard blood transfusion practices that reflected a highly statistically significant difference at $p<.001$ after guidelines implementation.

Table 9 revealed that there was a positive correlation between total levels of nurses' knowledge and their practice at $\mathrm{R}<$ 0.65 .

\section{Discussion}

Blood transfusion is an important aspect in daily nurses' clinical practice. Accordingly, periodic in-service training for nurses as a member of health care team is crucial to improve their knowledge and practices and help them in dealing with children receiving transfusion therapy (Herman, and Manno 2018). ${ }^{[30]}$ So, the present study was aimed to evaluate the effectiveness of implementing evidence based nursing practices guidelines on quality of nursing care and patients' safety as regards blood transfusion to improve transfusion practices and ensure safety. Therefore, the first step in improving the 
quality of patient care could be facilitated through investigating and documenting the current state of knowledge of blood transfusion. Thus, the purpose of this study was to investigate the current levels of knowledge of blood transfusion among hospital nurses. ${ }^{[5]}$ Also, Mosha et al. (2016) ${ }^{[36]}$ concluded that disseminating evidence through small group presentations is a strategy to guide clinical practice changes and involve the professional nurses in the process. EBP is essential for effective child's patient care. Promoting EBP of BT in the critical care settings raises awareness about the importance of applying research findings into nursing practices.

Table 8. Comparison of mean score of nurses' competency level before and after implementation of evidence based guidelines for standard blood transfusion practices

\begin{tabular}{|c|c|c|c|}
\hline \multirow{3}{*}{ Items of Practices } & \multicolumn{2}{|c|}{ Nurses' Competency level $\geq 85 \%$} & \multirow{3}{*}{$t$-test } \\
\hline & Before & After & \\
\hline & Mean \pm SD & Mean \pm SD & \\
\hline \multicolumn{4}{|l|}{ The role of the nurse in the prevention and management of: } \\
\hline Mild reactions. & $55.4 \pm 15.8$ & $86.4 \pm 13.5$ & $13.1^{*}$ \\
\hline Acute transfusion reactions. & $52.7 \pm 14.9$ & $86.7 \pm 10.3$ & $16.9 *$ \\
\hline Hemolytic transfusion reaction. & $54.5 \pm 13.7$ & $73.04 \pm 16.8$ & $12.8 *$ \\
\hline Bacterial contamination and septic shock. & $53.5 \pm 15.1$ & $84.8 \pm 14.5$ & $16.04 *$ \\
\hline Transfusion associated circulatory overload. & $56.7 \pm 16.6$ & $87.7 \pm 10.0$ & $14.1^{*}$ \\
\hline Anaphylactic reaction. & $54.7 \pm 14.7$ & $86.4 \pm 10.4$ & $15.1^{*}$ \\
\hline Delayed complications of transfusion. & $52.4 \pm 14.4$ & $89.2 \pm 15.3$ & $13.3^{*}$ \\
\hline Delayed hemolytic transfusion reaction. & $53.5 \pm 15.1$ & $82.5 \pm 16.9$ & $11.2^{*}$ \\
\hline Post transfusion purpura. & $53.2 \pm 15.4$ & $87.1 \pm 11.1$ & $15.7^{*}$ \\
\hline Transfusion associated graft versus host disease. & $56.2 \pm 15.6$ & $87.3 \pm 10.4$ & $14.3^{*}$ \\
\hline Delayed complications (transfusion-transmitted infections). & $51.4 \pm 14.1$ & $85.6 \pm 14.3$ & $15.04 *$ \\
\hline \multicolumn{4}{|l|}{ Complications of massive transfusion: } \\
\hline $\begin{array}{l}\text { Management of shock and maintenance of intravascular volume. } \\
\text { Prevention and management of hypothermia. } \\
\text { Identification and management of citrate toxicity. }\end{array}$ & $51.7 \pm 14.5$ & $87.5 \pm 10.3$ & $13.5 *$ \\
\hline
\end{tabular}

Table 9. Correlation between total nurses knowledge and their total practices before and after implementation of evidence based guidelines for standard blood transfusion

\begin{tabular}{|c|c|c|c|c|c|c|c|c|c|c|c|}
\hline \multirow{4}{*}{ Practice } & \multicolumn{8}{|c|}{ Knowledge } & \multirow{4}{*}{$\begin{array}{l}\chi^{2} \\
\text { Test }\end{array}$} & \multirow{4}{*}{$\mathbf{R}$} & \multirow{4}{*}{ Sig. } \\
\hline & \multicolumn{4}{|c|}{ Before } & \multicolumn{4}{|c|}{ After } & & & \\
\hline & \multicolumn{2}{|c|}{ Satisfactory } & \multicolumn{2}{|c|}{ Unsatisfactory } & \multicolumn{2}{|c|}{ Satisfactory } & \multicolumn{2}{|c|}{ Unsatisfactory } & & & \\
\hline & No. & $\%$ & No. & $\%$ & No. & $\%$ & No. & $\%$ & & & \\
\hline Competent & 38 & 40 & 25 & 26.32 & 70 & 73.68 & 2 & 2.11 & 5.7 & 0.48 & $<.05^{*}$ \\
\hline Incompetent & 30 & 31.57 & 2 & 2.11 & 19 & 20 & 4 & 4.21 & 4.2 & 0.43 & $<.05^{*}$ \\
\hline Total & 68 & 71.57 & 27 & 28.43 & 89 & 93.68 & 6 & 6.32 & & & \\
\hline$\chi^{2}$ & \multicolumn{11}{|l|}{6.1} \\
\hline $\mathrm{R}$ & \multicolumn{11}{|c|}{0.50} \\
\hline Sig. & \multicolumn{11}{|c|}{$<.05^{*}$} \\
\hline
\end{tabular}

As regards the characteristics of the studied nurses (see Table 1) clarified that, the mean nurses' age was $30.99 \pm 6.12$, and more than half of them had nursing school diploma. These findings definitely supported by results of Brooks and Combest (2018), ${ }^{[31]}$ who reported that more than one third of the studied nurses aged $20-<30$ years old and their mean age was $26.4 \pm 8.0$ years, as well as more than half of them

had secondary nursing school diploma. These results could linked to the fact that, the wide base for nurses' education in Egypt is diploma and nursing secondary schools provide the hospitals with large number of graduated diploma nurses than other agencies such as nursing faculties and technical nursing institutes.

Regarding receiving previous training programs, the result 
of the present study showed that few of nurses received previous training programs related to blood transfusion. In my point of view this may be due to lack of in-service training programs, the staff nurses did not aware about the importance of blood transfusion and adverse events that may occur if an error occurred during transfusion and nurses having no time to attend extra training courses due to their workload. The training course for nurses about management of patient undertaking blood transfusion is very important to improve their knowledge and performance that has a positive effect on quality of care and patients' safety. This results was agreed with Hendy, Mohammed, and Marzouk (2017) ${ }^{[5]}$ whose study about nursing performance as regard caring for patients undergoing blood transfusion founded that most of nurses didn't receive training courses about blood transfusion so that, nurses had significant lack knowledge and performance for many aspects of blood transfusion as evidenced by very low mean score they achieved.

Concerning the nurses' years of experience, the present study revealed that most of the nurses their years of experience ranged between one year and less than 20 years with mean $9.28 \pm 5.31$ years. This result was inconsistent with Wrwick and Modi (2017) ${ }^{[32]}$ who clarified that half of nurses had three years of experience with mean $4.1 \pm 2.1$ year. In this context, Whitsett and Robichaux (2017) ${ }^{[33]}$ confirmed that, the years of experience are important in acquiring more performance and the more experienced nurses had a significant level of performance than the less experienced nurses.

On investigating nurses' knowledge as regards blood transfusion, Figure 1 illustrated that, the total mean score of nurses' knowledge before the guidelines implementation $71.53 \%$ compared to $93.32 \%$ that reflected significant improvement in all items of the nurses' knowledge after the guidelines implementation. This result may be attributed to the following reasons; inadequate courses related to blood transfusion services in undergraduate curriculum study, improper preparation for the nurses about blood transfusion, and also lack of continuous training for nurses.

Concerning mean score of satisfactory nurses' knowledge regarding to hazards of transfusion (see Table 3) displayed a highly significant difference was observed in nurses' knowledge before and after guidelines implementation at $p<.001$. This result could be interpreted as nurses become aware about dangerous of blood transfusion and the importance of refresh their knowledge through continuous staff training, beside adequate supervision from well-qualified supervisor nurses in blood administration. This result was coincide with finding of Dzik (2018) ${ }^{[17]}$ and Amin, Wilson and Hebert $(2019)^{[18]}$ who pointed out that more than three fourths of nurses whom not received training programs had poor level of knowledge regarding to BT.

In the current study (see Table 4) there was a significant improvement in the mean score of satisfactory nurses' knowledge regarding strategy for blood transfusion safety after guidelines implementation. In the same line, Omer (2015) and Mosha et al. (2016) ${ }^{[34,36]}$ pointed out that, nurses whom are responsible for administrating blood and blood products should be informed and educated about the risks, hazards and complications of blood transfusion and the actions that are taken, if these happens. Also, Busch, Korelitz and Schreiber $(2018)^{[7]}$ and Zaccheo (2017) ${ }^{[37]}$ stressed that blood transfusion hazards must be managed promptly by staff who are knowledgeable of policies and procedures and have access to the correct blood transfusion supplies and facilities. As well as, Hijji et al. (2017) ${ }^{[35]}$ pointed out in study titled measuring knowledge of blood transfusion: a survey of Jordanian nurses that adequate knowledge is essential for safe practice and one of the current trends in nursing research emphasizes the importance of investigating nurses' knowledge of clinical procedures. Published information about nurses' blood transfusion knowledge in Jordan is lacking. Quality of care identified as a high priority area and this is where this area fits within Jordan's classifications of research priorities.

There was a statistical significant difference in the total score of nurses' competency level regarding blood transfusion practices before and after guidelines implementation (see Table 5). In this regards Amin, Wilson and Hebert (2019) ${ }^{[18]}$ who confirmed that the nurses became had adequate knowledge about the right methods for blood transfusion after training program. In addition to, available booklets containing basic knowledge and principles as regards blood transfusion and potential hazards of improper transfusion, as well as nurses were skillful in performing an immediate intervention in case of any hazards and transfusion reactions. These results were in agreement with results of Nugent (2016), ${ }^{[38]}$ and Gray, Howell and Pirie (2017), ${ }^{[39]}$ whom stated that nurses represent a core issue in establishing an efficient and safe transfusion services, so training of nurses as a member in health care team for blood transfusion services must be maintained. In the same context, Zaccheo (2017) ${ }^{[37]}$ mentioned that nursing approach is to implement evidence based into practice to improve the outcomes on patient care and help in understanding best practices, so nurses can provide efficient and competent care.

As regards, errors in nurses' practices before, during and after blood transfusion (see Table 6) revealed that significant improvement observed among the studied nurses after EB guidelines implementation that reflected the quality of care. 
This result was congruent with Amin, Wilson and Hebert (2019) ${ }^{[18]}$ who founded that, the nurses' performance related to BT procedures pre educational program were poor, whereas nurses doesn't warm blood bag before transfusion, doesn't check the intravenous access site continuously, and not observe the patient's vital signs in the first five minutes. Furthermore, Hijji et al. (2017) ${ }^{[35]}$ mentioned that, $80 \%$ can be due to human error and $42 \%$ of those errors occur when collecting and checking blood at the bedside. In addition, the risk of transfusion-related death was 5.6 per million blood components issued, and the risk of transfusion-related major morbidity was 63.5 per million blood components, the most common cause of death associated with transfusion was circulatory overload, right patient, right blood, right time, and checking at the bedside to prevent an error.

Conversely, statistically significant improvements in nurses practices were observed post educational program related to BT. In this context, Omer $(2015)^{[34]}$ pointed out that all nurses preprogram neglected to re-checks the physician's order before blood transfusion, conversely post program their performance was improved with highly statistical significance differences.

Finding of the current study (see Table 7) illustrated that, there was statistical significant difference before and after EB guidelines implementation regarding the mean score of competent nurses' practices if detecting any signs or symptoms of BT reactions. This result was paralleled with Deborah et al. (2016) ${ }^{[8]}$ who pointed out that implementation of EBNP to provide care for patients improving nearly $28 \%$ the outcomes for both the patients and health care system. Whereas, nursing management of child receiving blood transfusion is important. A comprehensive understanding of blood transfusion process and areas requiring special attention would be important to reduce the complications arising from blood transfusion. All staff must be aware of all aspect of care and the principles of safe effective patient identification, using aseptic technique during transfusion, proper documentation and adequate management of adverse reactions. ${ }^{[37]}$

In the same field, Omer $(2015)^{[34]}$ proved a significant improvement in nurses' competency level related to assessment for signs and symptoms of blood transfusion reaction post inservice training sessions. Furthermore, Gray et al. (2017) ${ }^{[39]}$ and Ward (2017) ${ }^{[40]}$ emphasized that, patients should closely followed after suspected signs or symptoms of blood transfusion reactions and document transfusion reaction in details, so that appropriate further action must be taken.

Result of the current study (see Table 8) indicated an improvement in nurses' competency level after implementing EBNP guidelines for standard blood transfusion that reflected a highly statistically significant difference. The contributing factors interpreted this result, as nurses' orientation of standard practices is important in improving the quality of BT administration and patient safety. El-Shiny $(2017)^{[41]}$ and Casey (2017) ${ }^{[42]}$ reported that, it is imperative that nurses administering blood transfusion should be adhere to the EB practice guidelines and institutional polices established to enhance patient safety. Additionally, the importance of written practices guidelines has emphasized by Marik and Corwin $(2018)^{[4]}$ and Gaitan (2017) ${ }^{[44]}$ whom recommended that, one way of increasing effectiveness of teaching and learning is using guidelines which provide a written explicit of knowledge and skills that were used for appropriate intervention. The nurse plays a critical role in ensuring that the transfusion of blood products is safe and that the patient is monitoring adequately for complications of massive transfusion. It is crucial that all members of the team are dedicated to prompt control of bleeding and early administration of appropriate blood components in a well-ordered way. ${ }^{[45]}$

Finding of the present study (see Table 9) revealed that there was a positive correlation between total level of nurses' knowledge and their practice $(R<0.65)$ before and after EB guidelines implementation. This finding may attributed to the fact that, most of nurses post EB guidelines implementation had adequate knowledge and skills about the proper assessment and interventions for patients during transfusion of blood, in addition to the importance of identifying and responding immediately to any adverse effect. Therefore, for nurses to provide high quality care and function effectively, they must have adequate knowledge that they actually use in practice ${ }^{[45]}$ This is because transfused patients continued to receive suboptimal care without nurses questioning the evidence base for practice So, it is important to the profession of nursing, to ensure that care delivery is evidence-based and nursing professionals should be equipped with the current evidence supporting BT practice in the critical care settings. ${ }^{[37]}$

\section{Conclusion}

The present study concluded that studied nurses at different pediatric care settings showed an improvement in their knowledge and practices that reflected on quality of nursing care and pediatric patients' safety regarding blood transfusion administration after implementation of evidence based clinical practices guidelines.

\subsection{Recommendations}

1) Empowering pediatric nurses with the current evidence and trends in blood transfusion practices may help in early diagnosis and proper intervention with treatment modalities when adverse events occur. 
2) Integrating evidence based education for pediatric nurses to improve quality of care patient's safety.

3) Providing regular periodic in-services training programs regarding blood transfusion for all nurses to keep them up to date to for safe and efficient administration.

4) Establishing a policy concerning evidence based transfusion practices guidelines, and this policy should be available at each hospital unit and each nurse should be clearly acquainted with this policy.
5) Maintaining documentation of dedicated transfusion training and competency assessment of hospital nursing staff involved in the transfusion process.

6) Emphasizing the importance for availability of evidence based guidelines for early recognition and management of transfusion adverse events in all health care settings where blood transfusion administered.

\section{CONFlicts OF INTEREST Disclosure}

The authors declare that there is no conflict of interest.

\section{REFERENCES}

[1] Akinkugbe O, Inwald D, New H. A Manual for Blood Conservation and Patient Blood Management. In: All Blood Counts, Patient consent (children). Chapter 9. Thomas, J. Thompson , TFM Publishing Ltd., Shrewsbury. 206; 127-140.

[2] Singapore Ministry of Health: Clinical blood transfusion. Executive summary of recommendations. Singapore: 2019 Jan. Available from: https://www.guidelinecentral .com/summaries/clinica 1-blood-transfusion/\#section-442.MOH_Inf @MOH.gov.s g

[3] Melnyk BM, Fineout-Overholt E. Evidence-based practice in nursing $\&$ healthcare, a guide to best practice. Philadelphia, PA: Lippincott Williams \& Wilkins; 2015; 1223-1227.

[4] Vincent JL, Piagnerelli M. Transfusion in the Intensive Care Unit. Critical Care Medicine. 2016; 34(5): 96-100. PMid:16617264 https://doi.org/10.1097/01.CCM.0000214314.57109.CD

[5] Hendy EA, Mohammed SY, Marzouk SF. Nursing Performance as Regard Caring for Patients Undergoing Blood Transfusion: Exploratory Descriptive study. Egyptian Journal of Health Care. 2017; 8(1): 23 30 .

[6] World Health Organization. Blood Transfusion Handbook. Geneva; $2015 ; 15-20$.

[7] Busch P, Korelitz J, Schreiber B. The risk of transfusion-transmitted human immunodeficiency virus Transfusion Med Rev. 2018; 13: 154-79.

[8] Deborah O, Sheila B, Ken S, et al. Blood management: from evidence to implementation. Critical Care Nursing. January 2016; 9(1): 16-24. https://doi.org/10.1097/01.CCN.0000438649.28872.58

[9] Bielby L, Peterson D, Spigie T. Transfusion education for nurses and transfusion practitioners in Australia. International Society of Blood Transfusion (ISBT) Science Series. 2018.

[10] Yesilbalkan OU, Akyol A, Ozel F, et al. Assessing Knowledge of Nurses on Blood Transfusion in Turkey. International Journal of Caring Sciences. January-April 2019; 12(1): 521.

[11] DeYoung Examining KT. The Evidence for Frequency of Vital Sign Monitoring During Transfusion of Blood Products in the Stem Cell Transplant Patient Population. Biology of Blood and Bone Marrow Transplantation. February 2018; 19 (2 Supplement): 359. https://doi.org/10.1016/j.bbmt.2012.11.568

[12] Secher EL, Stensballe J, Afshari A. Transfusion in critically ill children: an ongoing dilemma. Acta Anaesthesiol Scand. 2018; 57: 684 691. PMid:23692309 https : //doi.org/10.1111/aas. 12131

[13] Hijji B, Parahoo K, Hussein M, et al. Knowledge of blood transfusion among nurses. Journal of Clinical Pediatric Nursing. 2016;
22: 2536-2550. PMid:22830641 https://doi.org/10.1111/j . 1365-2702.2012.04078.x

[14] Netzer G, Liu X, Harris A. Transfusion practice in the intensive care unit: a 10-year analysis. Transfusion. 2015; 50: 2125-34 PMid:20553436 https ://doi.org/10.1111/j.1537-2995.20 10.02721.x

[15] Simancas-Racines D, Oleas N, Vernooij R, et al. Quality of clinical practice guidelines about red blood cell transfusion. 2018 PMid:30511477 https : //doi.org/10.1111/jebm. 12330

[16] British Committee for Standards in Haematology (BSCH) Guidelines for the Clinical Use of Red Cell Transfusions. British Journal of Haematology. 2015; 89: 219-233.

[17] Dzik H. Transfusion safety in the hospital. Transfusion. 2018; 45: 1190-1199.

[18] Amin M, Wilson K, Hebert P. Does a perception of increased blood safety mean increased blood transfusion? An assessment of the risk in Canada. BMC Public Health. 2019; 3(6): 42.

[19] Stanworth S. Serious hazards of transfusion in pediatric critically ill. Manchester, UK. 2018.

[20] Murphy M, Stanworth S, Yazer M. Transfusion practice and safety: current status and possibilities for improvement. International Society of Blood Transfusion. 2019; 100: 66-79.

[21] Gurses P, Marsteller A, Ozok A. Using an interdisciplinary approach to identify factors that affect clinicians' compliance with evidencebased guidelines. Crit Care Med. 2018; 36: S282-91.

[22] Thomas J, Jensen L, Nahirniak S. Anemia and blood transfusion practices in the pediatric critically ill: a prospective cohort review. Heart Lung. 2019; 39: 227-45.

[23] Kahn J, Richardson K, Billett H. Inter-NICU variation in rates and management of thrombocytopenia among very low birthweight infants. J Perinatol. 2019; 26: 342-348.

[24] La Gamma F. Introduction to transfusion practices in neonates: risk, benefits, and alternatives. Semin Perinatol. 2016; 36(4): 223-224. PMid:22818541 https://doi.org/10.1053/j.semperi. 2012 .04 .001

[25] Desmet L, Lacroix J. Transfusion in pediatrics. Crit. Care Clin. 2019; 22: 227-316.

[26] Callum L, Merkley L, Coovadia S, et al. Experience with the medical event reporting system for transfusion children medicine (MERSTM) at three hospitals. Transfus Apher Sci. 2017; 34(4): 93-8.

[27] Huband S, Trigg E, Moores D. Practice in children's nursing, Guidelines for hospital. 2nd ed. Churchill Livingstone; London: 2018; 150-159.

[28] Love EM, Jones H, Williamson LM, et al. Serious hazards of pediatric blood transfusion Annual Report. 2016; 256-287. 
[29] Bowden R, Greenberg S. Pediatric nursing procedures, 2nd ed., Lippincott Williams and Wilkins company, Philadelphia: 2017; 133-131.

[30] Herman JH, Manno CS. Pediatric transfusion therapy. Bethesda, MD: AABB Press; 2018; 129-45.

[31] Brooks JP, Combest TG. In-service training is useful in teaching transfusion children medicine principles. Transfusion. 2018; 34(6): 719-32.

[32] Wrwick R, Modi N. Guidelines for the administration of blood products. Archives of Disease in Childhood. 2017; 62: 349-371.

[33] Whitsett CR, Robichaux MG. Assessment of blood administration procedures in different pediatric settings: Problems identified by direct observation and administrative incident reporting. 2017; 41: 581586. PMid:11346689 https://doi.org/10.1046/j.1537-299 $5.2001 .41050581 . \mathrm{x}$

[34] Omer A. Implementation of an in service training program for nurses given care to anemic children in pediatric hospital, M.D thesis, Ain Shams University. 2015.

[35] Hijji B, EOweis A, Rasha S, et al. Measuring Knowledge of Blood Transfusion: A Survey of Jordanian Nurses. American International Journal of Contemporary Research. October 2017.

[36] Mosha D, Poulsen A, Reyburn H, et al. Quality of pediatric blood transfusions in two district hospitals in Tanzania: a cross-sectional hospital based study. BMC Pediatrics. 2016. Available from: http: //www.biomedcentral.com/1471-2431/9/51 PMid:19682362 https://doi.org/10.1186/1471-2431-9-51
[37] Zaccheo M. Implementation of an Evidence-Based Blood Transfusion Education Program in the Intensive Care Unit: Evaluating Nursing Knowledge. Capstone Paper submitted in partial fulfillment of the requirements for the degree of Doctorate of Nursing Practice, Chatham University. 2017.

[38] Nugent A. The need for continuing professional education for pediatric nurses Journal of Advanced Nursing. 2016; (13): 451-467.

[39] Gray A, Howell C, Pirie E. Improving blood transfusion: a patientcentered approach. Nurse Stand. 2017; 15(24): 32-48.

[40] Ward, J. Using clinical focus guidelines to emphasize process of learning. Journal of Nursing Education. 2017; 34(7): 119-139.

[41] El-Shiny $\mathrm{H}$. Effect of implementing an orientation program for internship nurses. The Egyptian Medical Journal. 2017; 13(1): 25-30.

[42] Casey G. Blood transfusion: The high-risk life-saving therapy. Pediatric Nursing. 2017; 27(4): 25-28.

[43] Marik PE, Corwin HL. Efficacy of red blood cell transfusion in the critically ill children: a systematic review of the literature. Critical Care Pediatric Medicine. 2018; 56(8): 2661-2670.

[44] Gaitan J. Patient Blood Management an Evidence based Approach to the practice of Transfusion Medicine. Transfusion Medicine Services \& Blood Management Program Florida Hospital, Orlando, Florida 2017.

[45] Vasiliki K. Enhancing Transfusion Safety: Nurse's Role International Journal of Caring Sciences. 2017; 4(3): 114-119. 